\title{
Food, Memory, Community: Kerala as both 'Indian Ocean' Zone and as Agricultural Homeland
}

\section{Caroline Osella, SOAS (School of Oriental and African Studies) and}

Filippo Osella, Sussex University

\section{Introduction}

We approach this paper with the knowledge that Kerala (south-west coastal India) is widely regarded as an 'exceptional' state. Kerala's population is split roughly 20-20-60 between Christian, Muslim and Hindu-the latter here including Dalits and Other Backward Castes (OBCs) and is famed for its relative lack of communal violence. Almost uniquely, Kerala is a state in which cows may legally be slaughtered for meat. ${ }^{1}$ Indeed, in Kerala, where Brahmins (Malayali Namboodiris and a few long-time immigrants from other southern states) are a tiny majority, the fact that buffalo- and even beef-eating is practised among Hindu castes (even savarna Nayars) sits alongside other of the state's purportedly 'non-typical' features (matrilinity, high literacy). All this might make one wonder whether any ethnography from Kerala could ever be useful for helping to think through broader regional patterns.

So what about those relating to diet? If, as Pat Caplan (this issue) suggests, the 'base diet' of Tamils - even Christians and Muslims - is vegetarian and common, grouped around shared and iconically South Indian dishes such as idli-sambar, then the base diet of Kerala stands quite apart from what we stereotypically think of as 'South Indian food' in being non-vegetarian (rice and

\footnotetext{
${ }^{1}$ The slaughter of cows for beef is outlawed across India, with the exceptions of Kerala, West Bengal and the north-eastern states.
} 
fish). (That is, if we can even speak of a Malayali 'base' diet, since food styles in Kerala vary widely across region and community.) Yet it is the very nonhomegeneity of Kerala society and foodways, we argue, which most sharply highlights for us several themes which have importance across South Asia: the categorical and performative separation of communities; a reluctance to think beyond the nation-state and a pathologising of those who do; and ways in which different attitudes towards food/caste pollution beliefs foster or curtail sociality.

We have worked in Kerala since 1989 and have conducted lengthy residential fieldworks in two very different zones: rural central Travancore, the paddygrowing and Hindu-dominated heartland where Muslims are few and Christians are a significant minority; and Kozhikode town, a northern (Malabar) trading town where Muslims have a cultural dominance and numerical strength and where Christians are a tiny minority. The two sites contrast in several ways: Kozhikode is littoral and urban rather than rural with seasonally-flooded backwaters; and Kozhikode was part of Malabar under direct British colonial rule, whereas Travancore was a nominally independent Hindu princely state. In Travancore, issues of caste and Hindu cultural patterns are very strong; in Kozhikode we find a much stronger colonial trace on the physical and cultural landscape. Taking into account the influence of all these differences, still we have confidence that here we are tracing a generalised difference between food practices which are clearly socially located and which we can justifiably name 'Hindu' and 'Muslim'. Material is mostly based on daily fieldwork, but we have also conducted several interviews focused on questions of food and ideas about body type or character as well as on specific kitchen practices such as spicing. ${ }^{2}$

We are arguing for ethnographers to pay closer attention to local imaginings of food. We will describe the base diet and festival dishes which are most commonly prepared among non-Brahmin Hindu middle-ranking communities and those prepared among Muslims. Differences in dietary practice between communities in Kerala are glaring and are, we argue, indicative of increasing communalisation of all aspects of social life. This leads us to a second strand,

\footnotetext{
${ }^{2}$ We are grateful to our friend Chandrasekhar Thampy, who has brought his Kerala culinary knowledge to a close reading of this ethnography; and to Sraddha Chigateri, Amit Desai, Scott Reese, James Staples and Caroline Wilson for their helpful comments on earlier versions. We thank the ESRC, the AHRC and the Nuffield foundation for supporting various periods of research; and Kai Kresse, Scott Reese and Edward Simpson for giving us the opportunity to present the paper at their workshop 'Shifting the Meaning: Connectivity and Its Challenges in the Western Indian Ocean', held at Zentrum Moderner Orient (Berlin) on 22 May 2007, where workshop participants gave invaluable feedback.
} 
which relates to Kerala's coastal situation facing onto the Indian Ocean. We contend that the 'Indian Ocean' should be seen not so much as an empirically existing fact - nor even as a possible frame of analysis to be freely chosen by the researcher - as much as a state of mind or potential orientation. What an exploration of foodways shows is how this orientation is not evenly spread throughout contemporary Kerala society. Everyone in Kerala (a long narrow strip of land) is within easy reach of the coast - fresh fish is delivered daily throughout the state and is a core item in most diets - but not everybody chooses to think of themselves, in this coastal state, as 'living near to the sea' or, indeed, as connected to places around the Indian ocean. Non-fishing Hindu groups are more likely to imagine themselves as rooted in land and agriculture and to stress the region's connection to the mainland, even while enjoying eating fish daily. From an ethnographer's point of view, when thinking about place, what are under discussion are not empirically existing locations so much as imaginary zones which exaggerate perceived negative and positive characteristics. $^{3}$

In a similar way, ethnographic representation relies upon generalisation and glossing over exceptions and often begins from local stereotype itself. It is in this spirit, and prompted by our own utter amazement when we switched fieldsites, that we offer some broad-brush ethnography of food as we have experienced it during our time in Kerala. Specifically we explore 'Hindu' and 'Muslim' foods in Kerala ${ }^{4}$ - but with stress on typicality. The Muslims we know who adopt vegetarianism for reasons of health or cultural prestige and the city-dwelling high-caste Hindu Communist Party activist who protested, on reading our earlier ethnography of untouchability practices, ${ }^{5}$ 'My friends and I never think of caste when we are invited to a fellow party-worker's house to

\footnotetext{
${ }^{3}$ Thus, we have explored elsewhere (in press) ways in which people across Kerala are interested in and oriented towards three imagined zones: firstly, the 'homeland' of Kerala, almost inevitably romanticised and super-saturated with positive cultural meaning even as it also becomes, among Kerala's Gulf migrants, the subject of negative comparisons with potential destination states; secondly, the migration destination of West Asian Gulf states, actually very distinct and nuanced in migrant accounts of preferences and differences between Gulf states, but generalised into cultural imagining and when spoken of among migrants in opposition to Kerala as a generic Gulf; and thirdly, Europe/USA, another zone which is highly differentiated but from which difference is popularly elided in discourse in order to make it stand at a third point of a rhetorical 'cultural difference triangle' against the Gulf and Kerala. See C. Osella and F. Osella, "Where's Best for My Children"-_Home", "Gulf" or "the West"? What Family Migration Strategies from Kerala, India Tell Us About Transnationalism', in Susan Koshy and Tariq Modood (eds), South Asian Diasporas (New York and Oxford: Oxford University Press, forthcoming Spring 2008).

${ }^{4}$ 'Hindu' here is shorthand for Kerala's middle-ranking and majoritarian Hindu castes, mainly Nayars, Tiyyas and Izhavas. 'Muslim' denotes a wider group.

${ }^{5}$ F. Osella and C. Osella, Social Mobility in Kerala (London: Pluto, 2000).
} 
eat', are both set aside here in favour of exploring phenomena and attitudes which we have encountered far more often.

Close examination of ethnographic material on Kerala food practices (cuisine, serving, styles of hospitality) hint at ways in which Hindus tend to orient themselves inwards, towards both the nation and an imagined 'Indian culture', and towards the emotionally resonant $n a d u$ (homeland) of Kerala - troped, for example, through rice - while Muslim food cultures clearly and explicitly evoke south Indian Muslims' links across the ocean to Arab culture-troped, for example, through the use of silver serving platters and the drinking of the (Yemeni drink) cava. Such differences are recognised, carefully cultivated and celebrated as part of modern projects of forging essentialised and differentiated 'communities' (sammudayangal) within the nation. Kerala-wide shared food practices which stand iconically for this state's specificity within the nation and which mark out its difference from neighbouring states (e.g. fish curry and rice; coconut oil; more controversially, beef) would also be available to be used in either Kerala-wide or broader 'Indian Ocean' cultural imaginings. We find, however, that items like coconut are imagined and sentimentalised as specifically 'Kairali', with similarities to foodways in other Indian ocean locations (even neighbouring Sri Lanka) left suppressed or unknown. Beefeating, meanwhile, while widely practised, is never celebrated or even mentioned as part of 'Kairali culture'.

We are persuaded, then, by Bourdieu's insistence that different social groups express their distinctive social habitus through material practices such as food, ${ }^{6}$ and by Sutton's exploration of food (in the tradition of embodiment studies ${ }^{7}$ ) as productive of the phenomenon of food memory. ${ }^{8}$ This stress on memory and habit does not, of course, mean that food cultures are static. The insistence upon the 'authenticity' and centrality of certain items which must have been, at one point, 'new' or 'foreign', is common across India - as has been amply demonstrated by Achaya and recently discussed by Nandy. ${ }^{9}$ A wilful denial of the fact of innovation and its subordination to a discourse of the 'traditional' is, after all, a very widespread phenomenon and evident in other arenas, such as

\footnotetext{
${ }^{6}$ P. Bourdieu, Distinction: A Social Critique of the Judgement of Taste (trans. R. Nice) (London: Routledge, 1984).

${ }^{7}$ Such as P. Connerton, How Societies Remember (New York: Cambridge University Press, 1989); or P. Stoller, Embodying Colonial Memories (New York: Routledge, 1995).

${ }^{8}$ David E. Sutton, Remembrance of Repasts: An Anthropology of Food and Memory (Oxford: Berg, 2001).

${ }^{9}$ K.T. Achaya, Indian Food: A Historical Companion (Delhi: Oxford University Press, 1994); K.T. Achaya, The Food Industries of British India (Delhi: Oxford University Press, 1994); and A. Nandy, 'The Changing Popular Culture of Indian Food: Preliminary Notes', in South Asia Research, Vol.24, no.1 (2004), pp.9-19.
} 
Hindu ritual practice. ${ }^{10}$ It is by now sociological commonsense that appeals to the 'traditional' and an imagined static cultural core are themselves part of the modern consciousness. In matters of food, this constructed 'traditional' seems over the twentieth century to have congealed into a series of food cultures which are increasingly communalised and in which Kerala Hindu expressions of that communalisation have become increasingly disciplined by Brahminical food values, leading up to recent attempts to extend the Hindu fundamentalist 'beef ban' to Kerala. ${ }^{11}$

Sutton points us towards reasons why food is so particularly embedded in community. ${ }^{12}$ 'Food memory' breaks analytic distinctions between the ritual and the everyday: it brings ritualised behaviours into mundane situations such as the noontime meal and it intensifies the work of ritual through bringing foodstuffs into it. Offers and exchanges of food between people also internalise social relations and allegiances and hence make them at once both deeply intimate and also obligatory. Sutton also accounts for the extraordinary power of food memory as partly due to synesthesia-the crossing or synthesis of different sense registers. ${ }^{13}$ Food engages and crosses smell, vision, taste, touch and even hearing. Yet, Sutton points out, taste and smell (unlike the modern European dominant sense of vision-codified into colours, shapes etc.) 'have relatively few verbalized categories associated with them ...they instead become evocative of social situations with which they are associated'. ${ }^{14}$ A feedback loop thereby exists between the situation in which, and the people with whom, one prepares, shares and eats food - and the food itself.

The centrality of food is also expressed at length in texts exploring the Hindu classical notion of rasa which lays the very foundations of Indian aesthetic theory, as discussed by Richard Schechner. ${ }^{15}$ Food engages and crosses smell, vision, taste, touch and even hearing. Sutton's synesthesia is evident in eating, but we take as also important here the existence of a dominant performance

\footnotetext{
${ }^{10}$ F. Osella and C. Osella, 'Migration and the Commoditisation of Ritual: Sacrifice, Spectacle and Contestations in Kerala, India', in Contributions to Indian Sociology, Vol.37, nos.1-2 (2003), pp.109-39 [http://cis.sagepub.com/cgi/content/abstract/37/1-2/109, accessed 19 Dec. 2007].

${ }^{11}$ See Chigateri (this issue) for details of the outlawing of cow slaughter and the marginality of beef consumption across India.

${ }^{12}$ Sutton, Remembrance of Repasts.

${ }^{13}$ Cf. N. Green, 'Breathing in India, c.1890', in Modern Asian Studies (Oct. 2007) [http://journals. cambridge.org $/$ download.php?file $=\% 2 F A S S \% 2 F S 0026749$ X07003125a.pdf\&code $=1 \mathrm{c} 8 \mathrm{~b} 120 \mathrm{a} 303847 \mathrm{bea} 6 \mathrm{~d}$ 566e33aeaf5e, accessed 13 Dec. 2007].

${ }^{14}$ Sutton, Remembrance of Repasts, p.17.

${ }^{15}$ R. Schechner, 'Rasaesthetics', in TDR: The Drama Review, Vol.45, no.3 (2001), pp.27-50.
} 
and artistic tradition-rasa - which does not dismiss what Schechner disarmingly labels the 'snout-to-belly-to-bowel' as beneath art, but makes it, rather, art's very foundation. ${ }^{16}$ Shechner makes the familiar point that the dominance of the visual in Europe should not be taken as a universal; his comparison of two foundational texts-Aristotle's Poetics with Bharata-muni's Natyasastramakes this evident.

Moreover, the belly, as Schechner helps us to appreciate with his succinct summary of recent neurobiological findings, does indeed have a brain (the 'ENS') ${ }^{17}$ which also helps us understand why and how phenomena like food memory or gastro-politics come to exist. ${ }^{18}$ We make these points in order to stress the highly privileged place of food as a cultural entity. In sum, the linkages between eating, emotion, memory and the social are both beyond dispute and likely to be difficult to override: as deeply rooted in the body as could be.

\section{Kerala and Its Food}

While food in Kerala remains intrinsic to caste, as in other locations, the use of different styles of food is particularly marked and has especial poignancy there in the differences between religious communities, especially Muslims and Hindus, and it is this which we take as our focus. Our research makes plain to us the extent to which Kerala's religious communities are rooted in different attitudes towards meat, fruit and vegetables, in different recipes and dishes, in preferences for different varieties of rice, and even in distinctive spicing practices and serving and eating styles. Hindu-Muslim difference seems to be the most salient boundary marked and made across Kerala. ${ }^{19}$

Nile Green has recently shown how even the imagined universal of breathing became differentiated and communalised over the nineteenth and twentieth

\footnotetext{
${ }^{16}$ While the Natyasastra is a Sanskrit text and the rasa tradition thus has a Hindu lineage, we can, along the lines taken by Nile Green (see for example 'Breathing in India'), understand that this tradition may well form part of a shared precolonial aesthetics.

17 'Snout-to-belly-to-bowel', the line of the gut and of eating and digestion, is also the line followed by the enteric nervous system (ENS), an independent nervous system in the gut containing 100 million neurons and connected to the central nervous system (CNS) via the vagus nerve but acting independently of the brain. See Schechner, 'Rasaesthetics'.

${ }^{18}$ A. Appadurai, 'Gastro-Politics in Hindu South Asia,' in American Ethnologist, Vol.8, no.3 (Aug. 1981), pp. $494-511$.

${ }^{19}$ Kerala Christians also have certain food items quite specific to them and cannot in any way be posited as 'mediating' between the other two groups. Issues of prohibition-notably pork-are also raised by consideration of Christian diets; for lack of space we cannot discuss these issues here.
} 
centuries, until finally modern Muslim sufi and Hindu yogic practice refused to recognise any commonality or shared history. This is part of what Green discusses as the communalisation of the body - a process which has proceeded across India at breakneck speed since Independence and to which the food practices we describe here contribute. ${ }^{20}$ Under the modernist regime of purification of religious and caste identities, Hindus have increasingly normalised and propagated vegetarianism, while Muslims have been pushed to the margins, left socially 'backward' and their religious and cultural practices increasingly stigmatised. ${ }^{21}$ The cultivation and focus on Hindu-Muslim differences which we observe in contemporary Kerala foodways are then closely linked to post-Independence imaginings of the Indian nation which marginalise Muslim citizens and write their cultural practices out of the nation (imagined, for example, through the dominance of Hindu tropes of vegetarianism or hierarchical hospitality feeding). This, in turn, has led to an increasing communalisation of Hindu-Muslim identities and relationships; and put an especial nuance onto the post-1970s fillip in Muslim - Arab relations given by Gulf migration. Remembering and celebrating past Muslim glories as masters of trade with the Arab world, and taking succour from the contemporary rise of Gulf Arabs - super-wealthy modern Muslims-help mitigate the stigma and social disadvantage that attends being Muslim in contemporary India.

Food is then, as is only to be expected, used to unify and to separate communities. Among Malayali Hindus, caste separation and distinctiveness is clear in the nuanced gradations practiced and counted as significant between the most severe forms of Brahminical vegetarianism, which shun all bodily heating' foods (such as garlic) and even certain items thought to resemble meat or used ritually to symbolise flesh (e.g. pasta); through those middle-ranking communities (e.g. the Nayars) which partake of 'non-veg' in the everyday, but are strictly vegetarian on ceremonial and sacred occasions; artisan (Viswakarma) castes, where a Scheduled Caste (SC) state classification and low ritual status combine with food practices approaching the Brahminical; and Dalit castes which refuse to become caught up in ascetic one-upmanship or even give value to vegetarianism. ${ }^{22}$ But the voices of the latter remain, of course, muted.

\footnotetext{
${ }^{20}$ See Green, 'Breathing in India'.

${ }^{21}$ T. Hansen, Wages of Violence. Naming and Identity in Postcolonial Bombay (New York: Princeton, 2001); T. Hansen, 'The India That Does Not Shine', in ISIM Review, Vol.19 (Spring 2007), pp.50-1 [http:// www.isim.nl/files/Review_19/Review_19-50.pdf, accessed 13 Dec. 2007]; and E. Simpson, Muslim Society and the Western Indian Ocean: The Seafarers of Kachchh (London: Routledge, 2006).

${ }^{22}$ The usual caveats regarding the use of labels such as 'Hindu' or 'SC' apply here. Contemporary groupings, whether they are spoken of locally as jati or sammudayam, may not correspond to early nineteenth-century
} 
As Shraddha Chigateri (this issue) observes, the Hindu 'food hierarchy' remains intact and is one of the most vicious ways in which some Indians claim superiority over others. As we have shown elsewhere, Brahminical discourses about diet, character, skin colour, body type, religious life, suitable employment and so on are all drawn tightly together to stigmatise the low-caste and manual labouring poor, while counter-discourse is uneven and lacks force. $^{23}$

In Kerala, as elsewhere in India, Hindus often formalise the food hierarchy by placing food items into either a hot:cold distinction or into the Samkhya philosophers' system of the tri gunas or the three qualities. Here, sattvik is associated with ideas of whiteness, brightness, purity, coolness and so on; rajasik is associated with heat, vitality, energy, and the colour red; tamasik is associated with the colour black and with darkness, sluggishness, stupidity and impurity. Social hierarchies are neatly mapped onto this tripartite division over and over, and resistant discourses are few and weak, because the tri gunas system is so all-encompassing, complex and deeply-rooted in Hindu society (of central importance, for example, in Ayurvedic medicine). Questions of diet stand at the heart of these discourses on superior and inferior people: those who eat sattva and are sattva, and those who are not. ${ }^{24}$

It is also without doubt that vegetarianism remains one of the major strategies in projects of social mobility. Such processes are not limited to Hindu South

groupings and may not even have existed before modern state classifications. For details of how religious communities formed and the very category 'Hindu' came into being in Kerala, see M. Muralidharan, 'Hindu Community Formation in Kerala: Processes and Structures under Colonial Modernity', in South Indian Studies, No.2 (1996), pp.234-59. For discussions of how caste and communal identities became solidified and objectified from the late nineteenth century onwards, see for example N. Dirks, Castes of Mind: Colonialism and the Making of Modern India (Princeton: Princeton University Press, 2001); and C. Gupta, Sexuality, Obscenity, and Community: Women, Muslims, and the Hindu Public in Colonial India (Delhi: Permanent Black, 2002).

${ }^{23}$ F. Osella and C. Osella, 'Articulation of Physical and Social Bodies in Kerala', in Contributions to Indian Sociology (n.s.), Vol.30, no.1 (1996), pp.37-68; C. Osella and F. Osella, 'Quelques Points de Vue Malayalis sur l'Inné et l'Acquis au Kerala, Inde du Sud', in V. Bouiller and G. Tarabout (eds), Images du Corps dans le Monde Hindou (Paris: CNRS Publications, 2003), Chap. 16 [http://www.cnrseditions.fr/Doc/Depliants/ D2271060605.pdf, accessed 18 Dec. 2007].

${ }^{24}$ We have found that Muslims, unsurprisingly, do not speak in terms of the tri gunas system. While some do recognise a hot:cold distinction, the benefits of coolness are downplayed. Indeed, the hot:cold framework is often given a reverse slant. Muslims often argued to us that meat and other 'hot' foods are necessary in order to keep the body and blood warm and moist, whereas Hindu food logics insist upon heatedness as a potentially dangerous value, and prefer the 'cool' end of the register. See Osella and Osella, 'Articulation of Physical and Social Bodies in Kerala', pp.37-68. This difference in evaluation of 'heat' is clear if we compare how they appear in Ayurvedic and Unani medicine respectively: while Ayurveda seeks to maximise coolness in the body, Unani works to produce warmth. For the most part, however, Kerala Muslims seem to be much less rooted in the logics of Unani thought than are their Hindu counterparts in Ayurveda. 
Asia: Martin-i-Pardo has shown how an encroaching 'global Hinduism' which insists upon vegetarianism and which claims for itself, alone, Hindu cultural authenticity, is de-legitimising the Trinidadian longstanding 'colombo cabri'. The latter is a spicy meat stew which was formerly acknowledged as authentically Indian, since it was brought by migrants from India in the 1800s. It represented a form of embodied history, as it was passed on among migrants as (embodied) recipe through cooking instruction, was widely eaten and enjoyed among Trinidadian Hindus, and was used in ancestor worship rituals and so on. This changed in the 1980s, with the rise of 'globalist Hinduism' and the introduction of the 'vegetarian meal' which claimed superiority and began to de-legitimise 'colombo cabri' as no longer 'proper Hindu' food. ${ }^{25}$

\section{Hindu Foods and the Food Hierarchy}

Let us begin head-on with the issue of vegetarianism. Kerala's Namboodiri Brahmins sometimes surprise those familiar with other Indian Brahmin communities by the extent of their orthopraxy. ${ }^{26}$ In dietary matters, too, most Namboodiris pride themselves on their orthopraxy and strict vegetarianism, which is rooted in avoidance of foods classified as 'hot' or 'rajasik' and hence extends beyond simple vegetarianism towards avoidance of a range of items, including tamarind and garlic. Namboodiri food is sweet and bland, the curries quite distinctive. One Brahmin explained:

Nayars, Izhavas and Christians eat rajasik sambar (lentil and vegetable curry with tamarind) and fish. Harijans, they don't stick to rajasik; they're like Muslims, they eat anything, they're all mixed up: they don't have a proper constitution (gunam), they're tamasik. ${ }^{27}$

Such Ayurvedic and Hindu textual ideas about the tri gunas is the commonest idiom used by Namboodiris to explain their food choices. But another strand of reasoning is also evident as contributing to their austere vegetarianism. Namboodiris follow the tantra agama sacred text, performing their worship

\footnotetext{
${ }^{25}$ Meritxell Martin-i-Pardo, 'Colombo Cabri or Vegetarian Meal: Wherein Lies the Power?', in Anthropology of Food, Vol.5 (May 2006) [http://aof.revues.org/document89.html, accessed 13 Dec. 2007].

${ }^{26}$ As recently as the 1980 s, we found lengthy initiation rituals routinely conducted for Namboodiri boys, in contrast to most other Indian Brahman communities, which have dispensed with formal initiation and resorted to collapsing a thread-taking ceremony into marriage rites. See C. and F. Osella, Men and Masculinities in South India (London, New York: Anthem Press, 2007), p.29ff. See also E. Gallo, 'From Gods to Human Beings: Comparative Analysis of the Social Transformations of the Nambuthiri Brahmins of Central Kerala', unpublished PhD thesis, University of Siena, 2003.

${ }^{27}$ To recap, sattvik = white, pure; rajasik = red, heating; tamasik = black, polluted and sluggish.
} 
(puja) using the Sri-chakra diagram but taking the misra-marga or third way, which is outwardly 'right-handed' but 'innerly' 'left-handed'. This inclines them to be highly sensitised to issues of substitution and resemblance; for example, they will use dried grapes as substitute for the ('left-handed') alcohol in performing their sakti puja. It is for this reason that they assiduously avoid certain substances, which have 'secret' esoteric meanings if used in puja. One such item is ada, a lasagne-style pasta sheet commonly used to make a rich dark jaggery payasam, a sweet pudding. ${ }^{28}$ The payasam made with ada may be served at weddings in all Hindu communities except those of the Namboodiris. They explain that they shun this item for their own payasams because ada is a symbolic equivalent or ritual substitute for mamsa - flesh — one of the 'left-handed' substances.

Namboodiri vegetarianism is then clearly associated both with superior ritual and esoteric knowledge and also with claims to a superior gunam (constitution or mind-body-spirit set). It is hence absolutely inextricable from claims to caste superiority and, indeed, the claims to superiority over other (non-vegetarian) religious communities made among Hindus more widely. Strict vegetarianism is framed in discourse in terms of personal and caste purity and claims to higher levels of spiritual evolution. Some Brahmins asserted to us that they are superior to other castes because they are sattvik and that this is demonstrated by their preference for sattvik food, which outsiders often find tasteless and unappealing (when invited, for example, to a Brahmin wedding). Other Brahmins assert that, because they eat sattvik food, they are sattvik and therefore superior. The reasoning is circular; there is no linear cause-effect relationship. Brahmins are sattvik, their food is sattvik: to ask which came first is to ask about the chicken and the egg. Brahminical logics here are closed and holistic and present morality as a just-so story in which others are naturally inferior, and doomed ever to be so. Those individuals who attempt to improve and purify themselves, seeking to become sattvik by adopting vegetarianism, are in the eyes of most Brahmins (and such non-Brahmin experts in traditional knowledge as vaidyans-Ayurvedic medicine practitioners-or jolsyansastrologers) guilty of incoherence and in any case doomed to failure. ${ }^{29}$

Non-Brahmin Hindus, almost all of whom by preference will eat fish daily and meat often - including, in many homes, beef and buffalo - also commonly say that sattvik food produces sattvik natures. But at the same time, they do not like or generally eat this food themselves. If quizzed, they often deny that their rajasik non-vegetarian food is inferior to a Brahmin diet. If away from home,

\footnotetext{
${ }^{28}$ Ada itself is a modern industrially-manufactured substitute for beaten riceflour fried cakes.

${ }^{29}$ Osella and Osella, 'Quelques Points de Vue Malayalis sur l'Inné et l'Acquis', Chap. 16.
} 
non-Brahmins will refuse to eat in a Brahmin (vegetarian) hotel, arguing that vegetarian food is not good for their bodies, fails to give nourishment and strength and is utterly tasteless (rasam illa, n.b. from Sanskrit rasa, discussed above). Yet while non-Brahmin Hindus are unwilling to eat the bland sattvik vegetarian food of Namboodiris, even on occasions of ritual purity, and while they may sometimes contest claims that rajasik is inferior as a quality, attributing all negatives to the quality of tamasik alone, they more often simplify the tri gunas system down into a simple hot:cold opposition, a food distinction which cuts right across India. Among Hindus, cold foods may be acknowledged as purer and productive of qualities such as calmness and intelligence, while hot foods may be ambivalent: good for some people, such as men who must labour, post-delivery women who are dangerously cool and in need of heating, newlyweds who must raise their thermostat and be 'hot', desirous; and bad for others, such as widows, who must not inflame their sexual appetites, or violent people — who should be seeking to calm themselves.

But even when the tri gunas classification is brought down to its simplest and panIndian form, as a binary hot: cold opposition, food classifications operate according to fuzzy logics and shifting evaluations. Several anthropologists have tried to systematise knowledge about food - by collecting lists of hot and cold foods, for example. Dalits told us that onions were cold food; Brahmins told us that they were hot; Vaidyans told us that the red ones are cold, but all others are hot; many people told us that they had never thought about it: some guessed that onions would be hot, others that they would be cold. Beck, writing over thirty years ago, ${ }^{30}$ lists onions as cold; we would not know where to place onions in a food classification chart and would not even presume to delineate one. The logics here are contradictory, ambiguous: it does not matter, because different pieces of knowledge will be called upon according to context. Non-Brahmins retain the right to be ambivalent about the question of whether rajasik food is actually inferior to sattvik. When trying to whiten a child's skin, a family will feed him or her milk and yoghurt, because these foods are known by all to be sattvik, and hence pure and productive of white skin. When talking about their own skin darkness (a continual anxiety among Malayalis), the same people may then deny that skin colour has anything to do with diet or purity.

Dalits (ex-untouchables) may sometimes challenge the dominant evaluations. They may deny that vegetarianism, sattva, coolness - or even purity - are superior, but such claims are unlikely to be countenanced (or made public)

\footnotetext{
${ }^{30}$ Brenda Beck, 'Colour and Heat in a South Indian Ritual', in Man (n.s.), Vol.4, no.4 (Dec. 1969), pp.55372.
} 
outside the Dalit colony, and may not even convince Dalits themselves. When we ran into Monachan at a Pulaya temple festival he was drunk senseless on cheap arrack, and told Filippo, laughing: 'Oh yes, no problem to me, I can drink rum, whisky, brandy, Tic 20 (insecticide), Factamphos (chemical fertiliser), anything. I can drink it all'. The strength sometimes claimed by Dalits, as opposed to higher castes, is that they are able to deal with poisons and tamasik substances - to take rubbish into their bodies. This is witnessed by their ability to work in the paddy fields with poisonous chemicals and to drink cheap adulterated liquor, as well as by their wide-ranging diet, which (because of poverty and shortage) may include tamasik items such as leftover stale rice, frogs and cats. However, in contrast to priests, astrologers and Ayurvedic doctors, who all by virtue of ritual knowledge have the means to neutralise or deflect the poisons which they encounter, in the logics of the Hindu food hierarchy, the residue of filth remains in the Dalit body, staining it. ${ }^{31}$

Unlike members of the middle castes, who (also lacking specialist knowledge to defeat poisons) try to avoid places and situations of bad influence, a Dalit is forced by work and residence into daily close contact with dirt, poisonous chemicals, bad spirits, disease, and so on. Some Dalits proudly claim the power to mop-up, endure, and deal with anything. The dispute, then, is about whether this particular power or attribute is going to be respected and accorded recognition as a talent, sneered at as a talent nobody in their right mind would want to have, or simply labelled as a fault. The outcome, it turns out, depends upon the actor. When the dark-skinned god Siva saves the universe from cosmic poisoning, the world is grateful and stays noisily awake for the whole night of the Sivaratri festival lest their lord fall asleep and succumb to the effects of the venom; but when dark-skinned labourers deal with mundane poisons, nobody is grateful or cares whether or not they are able to resist. In 1974 twelve people (all Pulaya Dalit men) in the village where we worked died of pesticide poisoning after crop-spraying, but no compensation was paid, nor any public outcry raised. Of course, if there was no-one to mop-up dirt and no-one to endure the heat and poisons of the paddy fields, the village would rapidly starve and drown in refuse. Those who insist upon the superior value of local (nadan) food, and on eating rice grown from paddy fields which they own themselves, rely utterly upon the Dalit manual labour which produces the paddy. Such facts are always forgotten and, rather than gratitude, it is unmitigated and deep stigma which follows those who labour in the fields and deal with tamasik substances. Middle-ranking and even low-ranking ex-untouchable castes (e.g. Izhavas)

${ }^{31}$ Cf. McKim Marriott (ed.), India Through Hindu Categories (New Delhi: Sage, 1990). 
work hard to follow the higher-caste example and avoid all practices associated with Dalits, from food to fashion. ${ }^{32}$

An index of the dominance in post-Independence India of high-caste Hinduism is the shift towards Brahminical values of sattva which we observe across Kerala's Hindu castes since the time of the religious reform and upward mobility movements of the 1920s and 1930s. The move adopted by almost all is to continue to practise non-vegetarianism in daily life, but to avoid nonvegetarian food during periods when ritual purity is important-as when preparing for or undertaking pilgrimage - and to offer a vegetarian feast (the sadhya) for all ritual occasions where purity is necessary, like house pujas or for celebrations such as betrothals.

A typical Hindu sadyha would be served on a banana leaf with, at its centre, a heap of rice made from boiled paddy-Kerala's red rice (chambavu or kutteri) for preference, 'big' white rice if the more costly red is unavailable. Of course, one wants to know the provenance of the paddy which forms the main item (and naturally nadan rice is preferred): first choice, one's own paddy; next choice, paddy grown in the village itself; last choices, rice coming from elsewhere in Kerala or even imported from outside the state. Over the rice are poured first a mild yellow parippu (dal) curry and a little ghee, then the hot and spicy tamarind and lentil sambar, with root vegetables and drumsticks. Around the edge of the rice mound, in a strict left-to-right order along the top of the leaf, come firstly the pickles and side curries: the pickles of inji (ginger); narangu (lemon); kadumanga (green mango); then small portions of side-curries of pachadi (creamy and sour with cucumber or bitter gourd); thoren (Travancore)/kaalen (Malabar) (scraped coconut dryfried with mustard seeds and green beans, plantain, cabbage or spinach); kichidi (creamy sour-sweet with pineapple or grapes); aviyal (coconut-based with carrot, drumstick and so on); then come a couple of fried chips (uperi) to snack on as an aperitif while waiting for the servers to come with rice and sambar: sarkara (ginger) or plantain; finally, a small puffy southern-style papadom to crumble into the rice mix; and a banana. There may also be a little potato curry (urulanga) and/or some red mung bean and marrow creamy curry (olen).

Servers move around while people are working their way through the meal, offering more rice and sambar. There are likely to be two or more sittings,

\footnotetext{
${ }^{32}$ F. Osella and C. Osella, 'From Transience to Immanence: Consumption, Life-Cycle and Social Mobility in Kerala, South India', in Modern Asian Studies, Vol.33, no.4 (1999), pp.989-1020.
} 
with higher-status people eating earlier and others waiting their turn. People sit in long lines to eat quickly and without conversation, calling servers peremptorily if they want more sambar, more rice, another side-curry helping. After a while, the servers bring rasam, a fiery peppery thin broth and ezhusseri (Malabar) or pulissery (Travancore), hot and sour yellow yoghurtbased curries made with mango. At last, one or more liquid puddings (payasams) are served onto the by-now-eaten-clean leaf: pal payasam, white and milk-based; semia, fragrant with cardamom and enriched with fried vermicelli; ada, made with flat pasta sheets; kadala, lentil and jaggery. Guests now peel and squish their banana into the payasam, to thicken it and make it easier to eat this liquid pudding by hand. Many guests will ask for more hot and sweet sticky lime chutney to eat with their payasam, to cut the sweetness and add an 'edge'-enhance the rasam. Finally, servers will offer moru, a drink which cleans the palate: thin buttermilk made spicy with plenty of split fresh green chillis, shavings of raw ginger and aromatic with curry leaves. This feast, then, is vegetarian, but it is anything but bland and it offers a wealth of rajasik flavour sensations: chilli, tamarind, garlic, ginger, heavy spicing.

We note here that rice and sambar, a daily staple in non-Brahmin Hindu homes, also makes the centrepiece of the sadhya feast. What makes sadhya different is that fish fry or fish curry, the other great daily foods, are avoided, while one classic vegetarian dish-parippu (dal) - is added instead, and the variety of koothu curries or side dishes becomes extended. The sadhya, whose centrepiece is a pile of 'big rice'-Kerala's unhusked paddy rice - is basically an assemblage of local and homegrown foodstuffs and is directly continuous with the daily diet, with a nod towards the demands of reformed Hinduism by the purging out of fish.

The staple daily house meal of rice-sambar plus fish fry or fish curry is both non-vegetarian and non-sattvik in its spicing and sourness, and hence directly challenges Namboodiri food logics. But at the same time, the twentieth-century adoption of vegetarianism across a range of situations even by Kerala's lower castes (such as OBC Izhavas) reveals a capitulation to Brahminical logics and to an underlying conviction that vegetarian and specifically sattvik foods are somehow 'purer', superior in some way to non-vegetarian. At the same time, this capitulation seems not to be linked to any dominance from Namboodiris as such, who are indeed a tiny part of Kerala's population. ${ }^{33}$ It is not at all the case that Namboodiri food has been adopted but simply that fish and meat

${ }^{33}$ Gallo, 'From Gods to Human Beings'. 
have been excluded from certain occasions. It is clear that Kerala Hindus' post1930 capitulation to vegetarian normativity is a product of an earlier wider Hindu reformism. The problem with the latter is that it then shades off all too quickly into the (highly modern) normative idea that vegetarianism is linked to values of 'non-violence', ${ }^{34}$ that it is productive of ascetic power and purity and that it confers spiritual superiority over non-vegetarians - an interpretation favoured by Gandhi and promoted since by pan-Indian Hindu nationalist organisations like the RSS (Rashtriya Swayamsevak Sangh), who have been highly active in Kerala villages. We are here arguing directly against Amit Desai (this issue) to suggest that contemporary vegetarianism cannot, sadly, be separated from its links to Hindu nationalism and fundamentalism. ${ }^{35}$ PostIndependence, Hindus have been drawn into the rhetorics of the nation, increasingly encouraged to act and think according to the logics of Hindu dominance, and have become accustomed to think according to the purificatory logics which figure the Indian nation not as plural but as Hindu and which insist upon purging the non-Hindu ${ }^{36}$ - even to the extent of imposing 'beef bans' on Christians and Muslims.

Thinking again about sambar, that lentil and vegetable curry in which hot and sour rajasik tastes (chilli, tamarind) are essential, this item is often thought of as the iconic South Indian Hindu food, a marker of Indian north-south difference. Sambar (with very different spicing) is eaten right across Tamilnadu and Kerala. It can be eaten for breakfast with idli (steamed fermented rice cakes), at noon with rice, as an evening snack with dosa (fried fermented rice batter pancakes); it appears as daily food and as a feast's centrepiece. And while some Christian communities, especially Syrians (Eastern Orthodox) also use sambar, the fact which becomes highly relevant here is that sambar is a dish which is almost never prepared or eaten by Muslims. Muslims' avoidance of sambar may well be linked to the fact that they shun the fermented rice- and lentil-based dishes (idli, dosa) which commonly accompany it. Muslim women will make appam, riceflour fried cakes, by using yeast instead of toddy as a raising agent, but they will not prepare dosa/idli, which are risen through

\footnotetext{
${ }^{34}$ We put 'non-violence' into inverted commas since, as clearly shown by Chigateri (this issue) cow worship and a discourse of vegetarianism as non-violence or respect for life is in reality wedded to several forms of caste-Hindu extreme violence (physical, structural, symbolic) against Dalits and others.

${ }^{35}$ We have discussed and argued this point with Amit Desai but none of us are convinced by each other's position. The tension between our (and Sraddha Chigateri's paper) and Amit Desai's paper is one of the interesting debates thrown up by the workshop and this collection.

${ }^{36}$ See for example Hansen, Wages of Violence: Naming and Identity in Postcolonial Bombay; E. Simpson. "Hindutva" as a Rural Planning Paradigm in Post-Earthquake Gujarat', in J. Zavos, A. Wyatt and V. Hewitt (eds), Cultural Mobilization and the Fragmentation of the Nation in Modern India (New Delhi: Oxford University Press, 2004), pp.135-65.
} 
natural fermentation overnight. Some women believed that toddy-alcohol, hence haram - was a necessary addition to idli/dosa; others expressed doubts that even the natural process of fermentation was somehow equivalent to alcohol production.

It is a sign of how much certain foods are community specific that, during all sixteen years working in Travancore, we never once ate biryani, while during our recent two full years residence in Kozhikode, only twice were we called to eat a rice-sambar meal on a banana leaf, something which we had eaten weekly at weddings and feasts while living in Travancore. We may as well have been in two different Keralas. One of our exceptional 'Kozhikode sambar' meals was, indeed, at a Hindu wedding; the other, we will describe below. ${ }^{37}$

\section{Food Crossings}

In Kozhikode, we often joined a motley group of determined cosmopolitans, a loose 'club', who met occasionally in a deserted countryside place outside town to drink, chat, sing and share unusual foods: foods which specifically would be shunned by anyone having scruples about purity, or anxieties about moving outside of the familiar. It is certainly significant that the core group of friends was solidly upper-middle-class and male and included a Konkani Brahmin, a Tamil Nadar, a Gujarati Patel, and two Anglo-Indians. But it also acted as an opening for those 'locals' (as even the Kozhikode-born Anglo-Indians refer to Malayalis) who wanted to move into a cosmopolitan space or try their hand at performing anti-communalism. The core group would always be joined by some Kozhikode Hindu and Muslim men. Occasionally, the menfolk's women and kids would be invited along. At one such leisurely Sunday afternoon 'family session' out in the countryside, away from any prying eyes, we rolled out a picnic which included split tongue, appam and stew, barotta, crabs, and a mystery food which we were all challenged to eat first and then guess what it was. It turned out to be blood pudding made with goat's blood: something which would upset the orthopraxy of just about any community and hence a master-stroke. Indeed, some club members did look a little green when the food's recipe was revealed. This was all washed down with whisky and beer, and a couple of the Anglo-Indian women present also drank a little beer. (The Hindu women did not, while no Muslim women ever attended the 'club'. Women, of course, bear the burdens of community identity, purity and gender

\footnotetext{
${ }^{37}$ Adrian Mayer is almost alone in being able to document details of some shifts over time in eating practices from the 1950s to the 1970s. See A. Mayer, 'Caste in an Indian Village: Change and Continuity 1954-1992', in C.J. Fuller (ed.), Caste Today (New Delhi: Oxford University Press, 1996), pp.32-64.
} 
normativity and find it difficult to negotiate respectability with the sort of illicit and explicitly anti-communal behaviours which were going on here.)

Probably even more extraordinary was the Onam feast prepared in 2005 by one Kozhikode Muslim family we know well. Here, women took the lead. Watching local cable TV in the run-up to Onam, several women from the family decided that it would be great fun to stage a 'proper' vegetarian sadhya. Sadhyas are not part of Muslim culinary repertoires; and Onam is of course not celebrated by Muslims; for it commemorates the victory of the Hindu 'demon king' Mahabali who, in Hindu lore, founded Kerala. ${ }^{38}$ Contemporary Islamic reformist ulema even advise Muslims to refuse invitations from Hindu neighbours who may wish to call them to eat on thiruvonam. ${ }^{39}$ From the outset, then, this Muslim family's plan to make an Onam feast had the air of a daring and naughty secret. Recipes were sought from TV and magazines; issues of ingredients and spices discussed; what sort of rice should be used; how to serve and eat the meal. Phone lines between the main house and the outlying houses buzzed. All the things which would be embodied knowledge, habitus, part of the utterly everyday in any Hindu home, were here utterly unknown and excitingly exotic. Come the day, 14 women - sisters and cousins and niecesassembled early in the small old house out of town where the oldest woman still lives with her elder daughter, and away from the eyes of Kozhikode's Islamist reformists. Just two men were available to come and keep company for Filippo, all others being busy in the bazaar or away in the Gulf. The women set up a huge preparation kitchen in the main living room (the hall in Muslim speech-a central un-segregated place which both men and women may pass through). After three hours of light-hearted kitchen-work and more discussions, amid great giggling, several mats were put on the floor and banana leaves set out on them in the main hall for the womenfolk while a smaller mat and a couple of leaves were put out on the verandah for the menfolk. The men, used to eating at tables and chairs, groaned and complained as they lowered themselves to the floor, while the women laughingly insisted that this sadhya had to be done 'proper style'. (Hindus often - especially for ritual celebrations - eat sitting on the floor.) But we noticed that nobody here sat cross-legged or with legs stretched out in front, as Hindus may have done; people sat instead as if at namaz (Muslim prayer) - on their knees. We also noticed that two senior women first served food to everybody but that they then sat down so that

\footnotetext{
${ }^{38}$ F. Osella and C. Osella, 'The Return of King Mahabali: the Politics of Morality in South India', in C.J. Fuller and V. Benei (eds), The Everyday State and Society in India (Delhi: Social Science Press, 2006). ${ }^{39}$ See F. and C. Osella, 'Islamism and Social Reform in Kerala, South India', in Modern Asian Studies (Nov. 2007) [http://journals.cambridge.org/download.php?file $=\% 2$ FASS $\% 2 F S 0026749$ X07003198a.pdf\&code $=$ 5def4abac2a0341f28e851f47f408cbf, accessed 13 Dec. 2007].
} 
everybody could eat together in a large circle. This is quite different from the Hindu style of always leaving one or two women standing to serve and of diners eating sitting in a line, not looking at each other ${ }^{40}$ One can, we observe, only contort the body out of its habitus to a certain extent.

The whole occasion was memorably joyful and giggly, and a remarkable exercise in pointing up that in the contemporary communalised situation in India, one person's pure and normative vegetarian meal can become another's utterly scandalous moment of transgression. Just as Muslims sometimes enjoy a moment of exotic otherness by going into a vegetarian cafe to eat idli-sambar, so Hindus sometimes treat themselves to a biryani at a 'Muslim hotel' or beef fry at a 'Christian hotel'. But what is also significant here - and we will return later to this point - is that while Hindus may sneak a biryani at a Muslim hotel or enjoy a drop of brandy in a Christian neighbour's home, they keep their own homes and most especially kitchens free of such transgressions. Because the home and especially their kitchens are the locus of caste purity, they are especially protected. While the non-vegetarian Muslim family above could cook a vegetarian meal at home, a crossing from vegetarian to non-vegetarian in the home is not regarded as an equivalent act and is generally unthinkable. This highlights the point that Hindu ideas about the polluting qualities of meat, or the ritualised purity of the kitchen, severely limit Hindu possibilities for cosmopolitan experimentation with food. Indeed, the whole Hindu domestic anxiety about the provenance of foodstuffs, about caste purity and food 'quality' (in the tri gunas sense), about observing social hierarchies in feeding and serving, all mitigate against either culinary cosmopolitanism or a culture of domestic-based hospitality and commensality. All this stands in sharp contrast to Muslim food practices, which we now move on to describe.

\section{Muslim Foods}

Here we turn away from ethnography of Travancore Hindus, living on the seasonally-flooded backwater paddy lands, and move towards ethnography from Kozhikode, a Malabar port city where the Muslim community is strong in numbers and its cultural influence powerful. Malabar Muslim food itself is well-known outside the community and is highly specific. There are very many items especially associated with the Muslim community, including ghee rice, biryani (goat, chicken, beef or fish), meat stew (beef or chicken cooked in spiced coconut milk), samosas (tiny ones, made 50/50 with shredded beef and fried onions), beef dry fry, mussels in sauce or stuffed, battered and deep fried, and

${ }^{40}$ As discussed in Mayer, 'Caste in an Indian Village', pp.32-64. 
pathiri-flat cakes of rice or wheatflour. Apart from stew, by its very name announced as a colonial invention, the food items above are all utterly different from those cooked in Hindu and Christian kitchens. Beef is of course becoming increasingly taboo among Hindus. Rice plays a lesser part altogether in Muslim diets and the rice which Muslims prefer is not Kerala's unhusked paddy ('big rice') but imported longer-grained white rice-basmati or kaima. At the evening meal, rather than rice, pathiri made of rice or wheatflour are prepared; we note also that the wheatflour used is not India's common atta (full rough flour as used by Kerala's settler Gujaratis for chapatis) but is maida (refined and processed wheatflour, a highly modern manufactured product). Muslim food then moves away completely from the food logics observed in the nadan sadhya, where what is local, imagined as 'traditional' and whose provenance is known is valorised, with outside foods being subject to distrust. It points us instead towards a quite opposite set of values: an embrace of the new; an interest in imported items; a taste for innovation, including modern manufactured products.

Not only do Kozhikode Muslims accept new food influences, they seem actively to seek them out as part of their generalised interest in food, feasting and eating out. Caroline was astounded when she attended a cookery demonstration sponsored by Nestlé and attended by lower-middle-class Muslim women, women whose husbands may be doing low-level labour in the Gulf, or running or working in small shops in the bazaar. All of the women used Maggi readymade noodles regularly, and most of them also knew and praised Maggi prawn powder as a useful kitchen ingredient. Among Hindu and Christian communities, this level of sophistication and enthusiasm for the new is seen only among a much higher-level class fragment. ${ }^{41}$

Biryani is a must for weddings, for festivals like Eid, as a special dish offered to guests, and it also appears regularly at home, as a treat. Each Muslim district of Kerala has its own special style of preparing biryani. Just as Muslims may enjoy occasional forays into a Hindu vegetarian hotel to eat idli-sambar, so too do Hindus sometimes visit a Muslim hotel in order to enjoy biryani. Biryani is a dish in which meat and rice are cooked together with-in the Kozhikode version-very light spicing, a prodigious quantity of ghee-fried onions and a good amount of rose-water.

\footnotetext{
${ }^{41}$ See for example discussions in Pat Caplan, 'Food in Middle-Class Madras Households from the 1970s to the 1990s', in K. Cwiertka and B. Walraven (eds), Asian Food: The Global and the Local (Richmond: Curzon, 2002), pp.46-62.
} 
There is a 'proper' way of eating biryani: it should be served on a san, a large plate holding enough for eight people. Nowadays, the san is placed in the middle of a circle of people, who then help themselves. Muslims were fond of reminding us that if done properly, everybody should actually eat directly with the hand from the san, sharing one plate. Older people who remembered the days of Arab traders' and sailors' visits to the town remembered how trading and marriage alliances were solidified by a family's menfolk sitting around a san together with the visiting Arab guests. More recently, migrants who had been in the Gulf often fondly remembered eating in this 'one plate' fashion, even with their Arab bosses and patrons, who would sometimes offer a biryani-type meal of rice and meat (Arabic: mandhi) in the office on Fridays.

This style of eating, replicated in the Muslim domestic sphere, where family members sit together around a table and serve themselves and each other, is rather different from Hindu styles, where age hierarchies are often observed to separate people into different 'sittings', and where family women will generally hover standing around the table to serve food.

As much as the food items, styles of eating are also quite distinctive between different communities. At most Kerala schools, children take a clean handkerchief which they spread on their individual desks to eat lunch or a snack from. At schools in Kozhikode's Muslim quarter, the children are moved from their desks to eat and are made to sit in small circles on mats on the floor, in an Islamic/Arabic eating style. In ways like this, a particular bodily habitus is inculcated, and is made all the more potent by being associated with the synesthetic experience of eating. ${ }^{42}$

\section{Hospitality and Feasting-Embodied Memories of Arab Visitors?}

'Either we eat or we are talking about the food we'll eat!' Aslam joked when Filippo once commented on Kozhikode Muslims' partiality for 'parties'. Indeed one of the most striking differences for us on reaching Kozhikode, after our previous research stints in south Kerala, was the centrality of food in everyday Muslim sociality. When people - men particularly - meet, food is never too far away. The most common marker of Muslim sociality in contemporary Kozhikode is the sharing of a meal with friends. Entrenched in local rhetorics of community self-representation, this is not a recent

${ }^{42}$ As outlined in Pierre Bourdieu, The Logic of Practice (Cambridge: Polity Press, 1992). 
innovation. In stories purged of reference to their illicit elements (alcoholdrinking and card-gambling) men fondly remember how bazaar traders from the 1930s through to the 1970s would regularly take turns to host men-only meals in their godowns (warehouses) - prepared by hired cooks - for friends and business partners, including the Arab sailors, boat-owners and traders who used to spend half the year in Kozhikode. With the progressive decline of the bazaar economy, such large-scale events no longer take place, but groups of friends continue to meet regularly, often daily, in the evening. Every evening, after maghreb prayer, men get together in groups to exchange gossip, talk over daily political events or simply enjoy each other's company. Such groups of friends - who have known each other since childhood, who have been together at school and who sometimes are related to each othermeet every evening in the same place: a street corner; around a bench; outside someone's office. Some groups are more formalised-with names such as 'The Jolly Friends' or 'Tashkent ${ }^{43}$ — and rent out old shops for their daily meetings. Since Islamic reformism made serious inroads into the community the drinking and gambling has been abandoned, but feasting, being nonharam, remains a pleasure.

Men take turn to treat their friends either by bringing home-cooked food to their meeting place, or by meeting the cost of having a complete meal brought in from a hotel. Alongside this, men also invite friends to their houses for meals. These regular gatherings of friends, all entailing a strong expectation of reciprocity, are in a continuum with other gatherings - primarily iftar partieswhere sociality is underscored by the consumption of food.

Here we find interesting Paul Stoller's project of showing us what an embodied ethnography might look like - how our writing might change if we take seriously the injunction to take into account the sensuous nature of experience. He reminds us that we have made a hierarchy of the senses, placing vision at the top and asks us to stop this. We need, he argues, to understand that the body knows, the body remembers. Thinking about contemporary food cultures as sedimented practice and as embodied history (Bourdieu's habitus) encourages us to search in foodways for the traces of past encounters and influences. Connerton, in his study of how societies remember, has also shifted ethnographic attention towards the materiality of life and the ways in which the material becomes a repository of cultural memory. ${ }^{44}$

\footnotetext{
${ }^{43}$ Called so after the then Soviet town where an Indian foreign minister died unexpectedly during a visit.

${ }^{44}$ See for example Connerton, How Societies Remember; P. Stoller, Sensuous Scholarship (Philadelphia: University of Pennsylvania Press, 1997); Stoller, Embodying Colonial Memories; C. Classen, 'Foundations for
} 
We suggest then that one very powerful source of contemporary practice is the long (embodied) memory of lavish feasting organised by wealthy local traders to entertain Arab merchants regularly visiting the city. Here, 'Arab food' (a fantasy category which nowadays has taken on a quasi-mythical status) was served - according to respondents, prototypically a roasted goat stuffed with a chicken, in turn stuffed with hard-boiled eggs and minced meat. In coastal trading ports like Kozhikode, a deep history of encounters with Gulf Arabs lies at the heart of what it means to be Muslim (as we have explored elsewhere). ${ }^{45}$ Indeed, Muslims themselves draw on a rhetoric of specifically-Islamic hospitality and commensality. This is epitomised by the Arabs whose sociality is known through past trade and marriage links, through contemporary migration and from whom, indeed, many Kerala families claim descent. ${ }^{46}$

Another aspect of the continuing reconstitution of feasting groups, extrafamilial dinners and expanding circles of hospitality comes from a selfconsciously sociable ethos. Kozhikode Muslims pride themselves on knowing how to 'make jolly' and participate gracefully — as host or guest - in occasions of hospitality; this is felt to be both a community-specific characteristic and part of a properly-Islamic lifestyle. ${ }^{47}$ Here, hospitality becomes performative and indicates the degree to which Muslims themselves participate in the national cultural purificatory work of setting themselves clearly apart from Hindus. ${ }^{48}$ The latter are regularly chided among Muslims for being too 'family oriented'-if not altogether mean and selfish - through their exclusion of friends and neighbours from household feasting on celebratory occasions and their lack of a culture of domestic hospitality. Rhetoric aside, the fact is that no 'Indian' ethics of hospitality exist. Rather, there exist specific styles of hospitality, which are then very much tied into other factors such as embodied histories and the demands of performativity. Among Calicut Muslims, we have pointed to embodied memories of Arab feasting and hospitality; among

an Anthropology of the Senses', in International Social Sciences Journal, Vol.153 (1997), pp.401 - 12; and C. Classen, Worlds of Senses: Exploring Senses in History and Across Cultures (London: Routledge, 1993).

${ }^{45}$ F. and C. Osella, “I am Gulf!”: The Production of Cosmopolitanism among the Koyas of Kozhikode, Kerala', in E. Simpson and K. Kresse (eds), Struggling with History: Islam and Cosmopolitanism in the Western Indian Ocean (London: Hurst, 2007), pp.323-57.

${ }^{46}$ High-status Thangals-Hadrami sufi saints; or from alliances between Arab sailors/traders and local women.

${ }^{47}$ P. Sloane-White, 'The "Hospitable Home" in Urban Malay Life: A Sociable Site of Political and Economic Action', unpublished conference paper presented at panel no. 287, International Convention of Asia Scholars (ICAS), Kuala Lumpur, August 2007.

${ }^{48}$ Here we draw upon ideas about the imperative in modernity of undertaking cultural works of purification. See for example B. Latour, We Have Never Been Modern (Brighton: Harvester Wheatsheaf, 1993); and Z. Baumann, Modernity and Ambivalence (Cambridge: Polity Press, 1993). 
Hindus, issues of relative prestige, caste closure and so on make their mark. When Hindus entertain or are entertained, issues which cannot be side-stepped are those of food itself as always potentially dangerous (evil eye, pollution), and the fact that accepting anything from anybody outside the most intimate circle is an act fraught with ambivalence (potential loss of prestige, loss of purity). ${ }^{49}$

Offering a feast to friends is, we were often told, an act of religious merit for Muslims. Certainly, our Kozhikode friends took the chance to accumulate merit in a continual round of hosting each other-at home and in restaurants. You are likely not to know some of the people at any salkaram (dinner function) you attend. You may not always know all the people you invite to your own home for a feast (e.g. your son or husband may invite his friends and also friends of friends). While male guests may be friends or acquaintances outside the home, their womenfolk will often meet for the first time. Many salkarams are men-only; others invite men with their spouses and children. The salkaram is specifically to bring together friends, rather than family, and is one way in which Muslims' strong social networks are maintained, expanded and intensified. Parties we have attended or hosted included as their guests: a group of men active in community organisations, with their families; a new son-in-law and his friends with their wives; a pair of business partners with their own friends and families; a Gulf migrant newly-home on leave and reunited with his friends; a group of clandestine card-players enjoying a strictly men-only night out. All during Ramzan - iftar season - sociable eating out reaches frenetic levels.

We were invited to, and ourselves hosted, many family salkarams during our two years in Kozhikode; Filippo was invited to a men-only one almost weekly! The expectation that we ourselves would host is itself interesting; in all our years in Travancore, Hindu ritual purity observances meant that most people would not take even a glass of water in our house (as Catholics, we had no caste status of course, and were considered ritually equivalent to untouchable). Only our closest friends would take food - and that would be the tea and purchased bakery items which do not carry caste pollution; a rice meal cooked by Caroline would have been out of the question for anyone. ${ }^{50}$ By contrast, not only did many Muslims happily come to feasts hosted in our home, but people even

\footnotetext{
${ }^{49}$ J. Parry, "The Gift, the Indian Gift and the "Indian Gift", in Man (n.s.), Vol.21, no.3 (Sept. 1986), pp.453-73; and G. Raheja, The Poison in the Gift: Ritual, Prestation, and the Dominant Caste in a North Indian Village (Chicago: University of Chicago Press, 1988).

${ }^{50}$ We do not imply here that such attitudes are found among all Kerala Hindus: as noted above, city-dwelling Communist activists, for example, are keen to dissociate themselves from concerns about food pollution. Yet still, we maintain that food anxieties and caste pollution anxieties do remain widespread.
} 
insisted on trying foreign food. After one 'men-only' salkaram, menfolk asked for small parcels of pasta al ragu to take home to their wives and kids, so that they could also taste this unfamiliar and tasty novelty.

At a house-based salkaram, when everything for the meal is ready, the hostesses lay out on a large table in the central hall (unsegregated area) of the house a range of dishes, sweet and savoury. First one gender group, then the other, comes through to this central hall to take a china plate and serve themselves from the vast array of food. Usually (but by no means always) men come first to take food, then retire to the front room with their filled plates from the hall, so that women can come in and serve themselves; women then always take their plates back into the ground floor bedrooms, where they sit companionably on the beds to eat and feed their children. Men can then freely come back into the hall for second helpings and puddings. At the table, host, hostess and family helpers urge guests to take tastes of everything. Women of the host family, for whom seclusion is slightly relaxed during salkaram to allow for the practicalities of hospitality, move in and out of the bedrooms where women guests are eating to offer second helpings: 'What can I get you? Another pathiri? Did you try the chicken fry?' Women guests happily put in their requests for extra helpings, and the hostesses take away the plates to the hall, where men may be eating, to be refilled and returned. Often at this point, recipes and compliments are exchanged between women guests and the hostess.

All of this is strongly expressive of several aspects of specifically-Muslim sociality. The eating styles, dishes eaten, and serving practices are all highly particular and different in many striking aspects from the Hindu food habitus. Firstly, the very practice of inviting non-family members home, or of visiting unrelated people in order to eat in their homes, and of expecting people unknown to each other to sit together and eat together, is highly unlikely among Hindus. It is certainly not a common practice nor, if it were done, would it be expected to be enjoyable and relaxed, as it clearly is here. When Hindu families invite guests, those guests are likely to be served first in the company of just one family member, perhaps a senior male, as a sign of respect. The Muslim insistence that all (including the host family) eat contemporaneously (albeit in gender-segregated separate rooms) is highly significant. It underlines a sense of equality, a desire for sociable community, and a belief that food is a legitimate pleasure which should be enjoyed and shared in company: part of what is often expressed as an ethical value of 'making jolly'.

At a salkaram there will always be ghee rice and meat stew or biriyani, sometimes both; also pathiri, both rice and wheat. Sometimes there will be fried 
rice and chapati, slightly exotic 'non-Kerala' foods - but always a huge range of side dishes, at least seven, drawn from fried chicken, chicken curry, fish fry, seafood (mussels, crab), other meat such as beef fry or liver dry fry, and fried noodles. There will be pickles and coconut chutney, two or more puddings (custards, cakes, crème caramels), and finally, two great platters of salad and cut fruit. As well as the necessary 'typical' food items such as biryani, women also try to serve 'surprise', luxury or exotic foods. When unfamiliar items are offered, guests enjoy guessing what the ingredients are; there is a great sense of enjoyment, jollity and easy sociability at a salkaram. We have eaten whole goat's head, mushroom curry, goats' brains, stuffed whole roasted chicken, and - most amazing of all-tofu. The salkaram ethos is one of lavishness and luxury, clearly recalling the glory days when visiting Arabs-who might later become business partners, or even sons-in-law-visited. ${ }^{51}$ This lavishness may even spill over into waste and leftovers. Wanton luxury is something which reformist Muslims criticise and which those anxious to perform Islamic ethics sometimes mitigate by offering a feast at an orphanage to balance the 'lavishness' of their salkaram. It would be most unexpected for Hindu hospitality styles, even at feasts, to spill into wanton luxury: the hospitality here, as we observed above when describing the sadhya, is above all 'homely'. The ethos of hospitality among Hindus is more likely to be a simple offer to a single and well-known guest to 'Come home and eat', with a slightly special dish offered. Mixing people up, as at a salkaram, would be distasteful; lavishing huge amounts of cash on food - a transient consumable, unlike gold, or landis not felt to be a good use of money.

Serving buffet-style food, which is enthusiastically taken by guests, is also Muslim-specific. When eating out at Hindu homes, expressions of family prestige, caste pride and guest-host hierarchical etiquette demand that guests should express reluctance to eat; should be served (guests should never serve themselves, but should have their needs anticipated); should be seated at a table and attended by (standing) womenfolk; and should eat silently and speedily, generally appearing as though the food is not a concern or is actually forced upon them (i.e. one is not greedy). Hindu etiquette expects that a guest be honoured by being seated at the table and watched - even by three or four standing family members - while they eat; the host family's job here is not to eat with and keep company with the guest, but to ensure that the guest is

\footnotetext{
${ }^{51}$ Time which women are willing and expected to spend on food preparation is here another issue deserving of comment. When hosting a salkaram, women will marshal female relatives to help; helpers frequently come to stay overnight as preparation begins the day before the dinner. Thus, 'kitchen work' can typically occupy a group of around four to seven women for two days; it thereby becomes a site for female homosociality in its own right.
} 
treated respectfully and well fed, and that all needs (a glass of water, a towel to dry the hands) be anticipated and swiftly met. The Kerala Hindu and Christian habit of having food served onto a male guest's plate by a woman from the host family, who stands close by the guest, is felt among Muslims to be highly inappropriate. Salkaram guests are urged to taste foods, but are permitted to help themselves and choose what to eat. For Muslims, all who are in a room will be urged to sit and eat together; only the main hostesses move around to replenish plates, while other family members (including children) will gather to eat with guests.

The salkaram hostess'es concern to take plates from her female guests who are eating in the bedroom in order to take them to the table, where she will refill them, is also expressive of Muslims' utter disconnectedness from Hindu notions of purity and pollution. Among Hindus, plate-clearing or touching plates with leftover food on them is a deeply political act, shot through with ideas about jutha - pollution - and hierarchy. Salkaram guests' willingness to ask for more food and to express pleasure in eating again underlines Muslim freedom from purity anxieties or ambivalence about 'other people's food' and indicates a quite different sensibility - i.e. that food is a pleasure rather than a danger, and that one loses no prestige or face by expressing open appreciation of the other.

\section{Conclusions}

The range and richness of the food at a salkaram - lavish, novel, variedcontrasts strongly with the Hindu celebratory meal (sadhya) described above, which is a simple rice meal with a rigid set pattern of side-items. There is no room for innovation in a sadhya-'tradition' and familiarity are what is valued. Kozhikode Muslim food practices, both in terms of the items served and in the practice of forging ever-expanding social networks and circles of sociality (through encouraging salkaram invitations to friends-of-friends or relatives-of-relatives), display strong tendencies towards cosmopolitanism and adoption of the new.

Travancore Hindus express widespread distrust of food items felt to be imported or not traditional, and strenuously avoid commensality (even refusing to take a glass of water outside their own homes) because of purity anxieties. Given that such orthodox Hindu attitudes towards food and commensality represent the majoritarian position associated with the dominant religious community and with the nation's increasing projection and protection of 'Hindu values' and 'Indian traditions', Kerala's coastal Muslims' openness to outside influences - new foods, new people - is remarkable; it is notable and 
quite different from mainstream South Indian patterns, which tend towards conservatism, closure and valorisation of the familiar and the local.

The two contrasting styles embody the very diverse food habitus of these different sections of Kerala's community, and point towards their different orientations in space. Travancore's Hindus, although they are living in backwaters open to the sea and although they relish fish curry daily, still will not look to the sea-a place associated with low-status manual labourers, dirt and so on. ${ }^{52}$ They look resolutely towards the land and to what can be grown and eaten from there. Hindus' localism encompasses strong preferences for local (nadan) food, even to the extent of preferring to eat rice grown on their own plots. ${ }^{53}$ By contrast, Kozhikode's Muslims, a trading community with no romance of the land, look outwards to the sea. This is manifested not only in the great variety of seafood dishes they eat (mussels and crab are specialities) but also in their memories of the heyday of Arab trade and their enthusiasm for projects of making links towards a wider Muslim world. ${ }^{54}$

Sitting to eat in a line or a circle; sitting in single-sex or mixed groups; eating in relays according to a social hierarchy or together, simultaneously; serving oneself or being served; expressing relish or diffidence in eating food cooked by non-kin: all these are bodily indications of community affiliation and a community-specific vision of human relationships - as egalitarian or hierarchical, status as marked primarily by age and caste or by gender, outsiders as dangerous or to be welcomed. All these are fused into the powerful food memory which repeated shared meals will produce. ${ }^{55}$ Through meals, ethnicity is performed and produced, a particular habitus is inculcated, and a tight knot drawn which binds together a group of people with a type of food and a modality of eating it.

Eating from the san for biryani, or the banana leaf for sadhya, is what seals the meal as 'authentic' and locks it into a particular cultural locus. While the banana leaf looks inwards to the landscape of Kerala, with its ubiquitous banana and coconut trees, the san looks outwards towards the Indian Ocean and to the Arab world which first brought Islam and Muslim culture to

\footnotetext{
${ }^{52}$ Cf. Simpson, Muslim Society and the Western Indian Ocean: The Seafarers of Kachchh. It is, then, like the paddy fields discussed above, a place where low-status people and pollution are considered to lurk.

${ }_{53}$ Osella and Osella, 'From Transience to Immanence: Consumption, Life-Cycle and Social Mobility in Kerala, South India', pp.989-1020.

${ }^{54}$ Osella and Osella, “"I am Gulf!"', pp.323-57.

${ }^{55}$ Sutton, Remembrance of Repasts.
} 
Kerala - and introduced the practice of eating meat and rice together from one large shared plate.

We have noted that certain items are iconic and associated strongly with a community identity-idli-sambar, biryani. Interestingly, it is these very food items which are the ones people seem most attached to ${ }^{56}$ these are foods which evoke food memory, which comfort and provoke desire and appetite, which are the subject of nostalgic longing when away from home. Meanwhile, it is the distinctive festive community-identified foods which are the most highlyappreciated in open discourse and discussion about meals.

The fact of pointing up difference in discourse and in practice need not necessarily imply, however, a total community opposition. There is no necessary reason why sambar and biryani should have been picked as the principle items which are both preferred and made iconic. Firstly, there are many food items which are shared across Kerala and across all communities: stew, fish curry, chicken fry, barotta; secondly, as we have seen, people are willing to take each others' food, albeit often in a transgressive way, marked as mildly illicit and hence fun; thirdly, there are some shared ingredients used daily in all Kerala homes which, even if they finish up in different recipes, bring together food cultures. The fresh coconut which is grated and pounded on a large stone at the back of most Kerala houses daily as part of curry preparation is the example par excellence. Indeed, there are items which people are very attached to, to the point that they become utterly taken for granted. Coconut oil here is the prime example; any Malayali will insist that the cheap imported palm oil and artificial vegetable fats which are creeping in to replace this costly oil for daily cooking are inferior and do not give proper 'taste' to food. Many women add a dash of coconut oil into the palm oil pan so that at least some coconut oil taste will be enjoyed. The virtue of coconut oil in cooking is something utterly taken for granted right across Kerala and across all communities.

Yet despite all this potential for recognition of commonality, we find that people attach food memory not to the shared ingredients, like coconut oil, but to the distinctive finished dishes. The fact that there is actually a great deal of shared food culture across the state is muted in discourse.

\footnotetext{
${ }^{56}$ One Calicut Muslim noted how a 'progressive' relative had decided to break the monotony of biryanieating for days on end at a succession of family post-wedding feasts by serving up something different - a vegetarian sadhya. Guests were outraged rather than relieved! While food-crossings do occur, as in the transgressive Onam feast above, there is no place for them on occasions like weddings, where community is being objectified, produced and celebrated.
} 
People will talk about sadhya or biryani and highlight the distinctiveness of the dishes, rather than recognising or pointing out that both items require curry leaves-like coconut oil, another Kerala iconic ingredient, freely available to all and grown in many backyards. As outsiders, we find that the ubiquitous use of strongly-flavoured ingredients like curry leaves and coconut - and black pepper, of course $!^{57}$ — clearly both form people's palates right across Kerala and contribute to the sensual power of the evocative food memory.

Our argument here though is that, because these shared items are not appreciated as such by the people eating them, we cannot assume their salience. People are failing to recognise food commonality even within Kerala, across communities, 'forgetting' that almost everyone's daily base diet relies upon coconut, coconut or palm oil, fish, curry leaves and strong spicing. Malayalis work hard to make difference and ignore commonality; they work even more strenuously to uphold the nation, by ignoring or refuting culinary commonalities around the Indian Ocean region and imagining their foods as examples of 'Indian' diets. We are arguing then that if people are thinking of coconut oil or fish curry as specific to Kerala, then even if we, empirically, know this not to be the case, ${ }^{58}$ we must not treat 'fish curry' in ethnographic analysis as an 'Indian Ocean' item. We need to follow local evaluations of empirical issues - which may deny or be ignorant of Indian Ocean linkages. When Hindus suppress or ignore the commonalities between their food and that of their Kerala Muslim neighbours and when they similarly ignore continuities with Sri Lankan food $^{59}$ in favour of a tight localism, then we have to follow their line of reasoning about their own cultural forms and explore it. The question here becomes: why do people do this? The answer of course lies in the profoundly communalising experience of colonialism ${ }^{60}$ and the politics of nation. ${ }^{61}$

\footnotetext{
${ }^{57}$ For details of how important black pepper has been, see discussions, passim, in K.N. Chaudhury, Asia Before Europe: Economy and Civilisation of the Indian Ocean from the Rise of Islam to 1750 (Cambridge: Cambridge University Press, 1990).

${ }^{58}$ Rice with fish curry is eaten right across Indian Ocean coastal societies.

${ }^{59}$ For example Sri Lanka's (justifiably!) famous 'string hoppers' are the same as Kerala's 'iddiyappam' (southside) or 'nool puthu' (north-side).

${ }^{60}$ See for example B. Cohn, 'The Census, Social Structure and Objectification', in B. Cohn, An Anthropologist Among the Historians and Other Essays (New York and Delhi: Oxford University Press, 1987), pp.224-54; R. Inden, Imagining India (Oxford: Basil Blackwell, 1990); and Dirks, Castes of Mind.

${ }^{61}$ For interesting explorations of some issues raised here, see for example P. Roy, Indian Traffic: Identities in Question in Colonial and Postcolonial India (Berkeley: University of California Press, 1998); and Gupta, Sexuality, Obscenity, and Community: Women, Muslims, and the Hindu Public in Colonial India.
} 